\title{
Offering women a choice in induction of labour in case of an unfavorable cervix: a prospective cohort study
}

\author{
Ninon Dupuis ${ }^{1}$, Lola Loussert ${ }^{1}$, Pauline de Vries $^{2}$, Olivier Parant ${ }^{1}$, Christophe Vayssiere ${ }^{1}$, \\ and Paul Guerby ${ }^{1}$ \\ ${ }^{1} \mathrm{CHU}$ Toulouse \\ ${ }^{2}$ Leiden University Medical Center
}

June 1, 2021

\begin{abstract}
Objective: To evaluate women's choice in the method of labour induction between oral misoprostol, PGE2 pessary and the Foley catheter. To compare women's satisfaction according to their choice and to identify factors associated with patient satisfaction. Design: Prospective cohort study. Setting: Tertiary hospital in Toulouse, France, from July 2019 to October 2020. Population: All women admitted for labour induction at term, by either oral misoprostol, PGE2 pessary or Foley catheter. Methods: Women chose their preferred method. Before and after the delivery, they were asked to argument their choice and to evaluate their satisfaction through the use of questionnaires. Main outcome measures: Global level of satisfaction. Results: Of the 520 women included, $67,5 \%$ of women chose oral Misoprostol compared to $21 \%$ PGE2 pessary and $11.5 \%$ the Foley catheter. Regarding global satisfaction, we found no significant difference between the three groups: $78,4 \%, 68,8 \%$ and $71,2 \%$ ( $\mathrm{p}=0,091$ ) for respectively oral misoprostol, PGE2 pessary and Foley catheter. Factors that seem to improve women's satisfaction were nulliparity $(\mathrm{OR}=2.03,95 \% \mathrm{CI}[1.19-3.53])$, delivery within 24 hours after the start of induction $(\mathrm{OR}=3.46,95 \% \mathrm{CI}$. [2.02 - 6.14] ) and adequate information $(\mathrm{OR}=4.21,95 \% \mathrm{CI}[1.86-9.64])$. Factors associated with lower satisfaction rates were postpartum hemorrhage $(\mathrm{OR}=0.51,95 \% \mathrm{CI}[0.30-0.88])$ and caesarean section $(\mathrm{OR}=0.31,95 \% \mathrm{CI}[0.17$ - 0.54]). Conclusion: Women satisfaction rates were not different between the three methods, when chosen by the patients themselves. These finding should encourage caregivers to promote shared decision making when possible.
\end{abstract}

Offering women a choice in induction of labour in case of an unfavorable cervix: a prospective cohort study

Authors

N Dupuis, ${ }^{\text {a }}$ L Loussert, ${ }^{\text {a }}$ PLM de Vries, ${ }^{\mathrm{b}}$ O Parant,,${ }^{\mathrm{a}, \mathrm{c}}$ C Vayssière, ${ }^{\text {a,c }}$ P Guerby, ${ }^{\mathrm{a}, \mathrm{d}}$

${ }^{a}$ Department of Obstetrics and Gynecology, Paule de Viguier Hospital, CHU Toulouse,

Toulouse, France

b Department of obstetrics and gynaecology, Leiden University Medical Centre, Leiden, Netherlands

${ }^{\mathrm{c}}$ Inserm UMR1295 CERPOP (Center for Research in Epidemiology and POPulation Health), Team SPHERE, University Toulouse III, Toulouse, France

d Infinity CNRS Inserm UMR 1291, University Toulouse III, Toulouse, France, email: guerby.p@chutoulouse.fr

Corresponding author: Paul Guerby - guerby.p@chu-toulouse.fr

Running title: Women's choice for labour induction 


\begin{abstract}
Objective To evaluate women's choice in the method of labour induction between oral misoprostol, PGE2 pessary and the Foley catheter. To compare women's satisfaction according to their choice and to identify factors associated with patient satisfaction.
\end{abstract}

Design Prospective cohort study.

Setting Tertiary hospital in Toulouse, France, from July 2019 to October 2020.

Population All women admitted for labour induction at term, by either oral misoprostol, PGE2 pessary or Foley catheter.

Methods Women chose their preferred method. Before and after the delivery, they were asked to argument their choice and to evaluate their satisfaction through the use of questionnaires.

Main outcome measures Global level of satisfaction.

Results Of the 520 women included, $67,5 \%$ of women chose oral Misoprostol compared to $21 \%$ PGE2 pessary and $11.5 \%$ the Foley catheter. Regarding global satisfaction, we found no significant difference between the three groups: $78,4 \%, 68,8 \%$ and $71,2 \%(\mathrm{p}=0,091)$ for respectively oral misoprostol, PGE2 pessary and Foley catheter. Factors that seem to improve women's satisfaction were nulliparity (OR $=2.03,95 \%$ CI $[1.19$ $3.53])$, delivery within 24 hours after the start of induction ( $\mathrm{OR}=3.46,95 \% \mathrm{CI}$. [2.02 - 6.14]) and adequate information $(\mathrm{OR}=4.21,95 \% \mathrm{CI}[1.86$ - 9.64]). Factors associated with lower satisfaction rates were postpartum hemorrhage $(\mathrm{OR}=0.51,95 \% \mathrm{CI}[0.30-0.88])$ and caesarean section $(\mathrm{OR}=0.31,95 \% \mathrm{CI}[0.17-0.54])$.

Conclusion Women satisfaction rates were not different between the three methods, when chosen by the patients themselves. These finding should encourage caregivers to promote shared decision making when possible.

Tweetable abstract By offering women the choice about the method of labour induction, the level of satisfaction is similar for oral misoprostol, PGE2 pessary and Foley catheter.

Keywords

Induction of labour, satisfaction, choice, misoprostol, Foley catheter, intra vaginal prostaglandin E2, PGE2 pessary

\title{
INTRODUCTION
}

Several methods of labour induction have been described, including oral misoprostol, PGE2 pessary and Foley catheter. Nowadays, involving women in their own care appears essential, especially in obstetrical care such as labour induction.

The labour induction rate increased from $9.6 \%$ in 1990 to $27.1 \%$ in 2018 in the United States. This rate even rises to $37.8 \%$ in nulliparous women ${ }^{1,2}$. In England and Wales, induction of labour accounts for more than one in five deliveries, and this rate has been increasing over the past 20 years in high-income countries ${ }^{3,4}$. More than $60 \%$ of the total number of labour inductions need cervical ripening ${ }^{5,6}$. Finally, the recent demonstration of a potential benefit of elective induction of labour at 39 weeks may increase this trend and underline the importance of asking about women satisfaction and their place in the decision about the $\operatorname{method}^{7}$.

Most of the published studies compare induction methods one by one. However, neither the PROBAAT II trial ${ }^{8}$ nor a large meta-analysis of 96 randomized controlled trials ${ }^{9}$, could find a significant difference in obstetrical or neonatal outcome between each method of cervical ripening. In a recent meta-analysis, Alfirevic et al. reported that none of the methods is superior to the others regarding perinatal outcomes ${ }^{3}$. Management of labour induction with cervical ripening is very heterogeneous and can even vary within maternity wards, according to national guidelines and local practices. Standardizing practices was one of the objectives of the French and English guidelines in $2008^{10,11}$. Therefore, the identification of the best outcome is essential 
since different outcome measures have been used such as delivery within 24 hours, caesarean rate and total duration of labour induction.

In modern obstetrics, it is essential to consider women's opinions and to involve them in medical decision making, as it is associated with higher satisfaction rates ${ }^{11,12,13}$.

Several studies discussed women satisfaction concerning delivery by comparing spontaneous labour to induction of labour. These studied showed that labour induction might be associated with lower satisfaction ${ }^{14}$. However, no study has ever evaluated women satisfaction regarding labour induction after offering women the choice of the method of cervical ripening.

Lastly, Coates et al emphasized the importance of shared decision-making between clinicians and women and stated that the physician should empower women to be involved in decision-making such as induction of labour ${ }^{15}$. Therefore we decided to engage women in the decision-making process of the choice of the method of cervical ripening in our tertiary center.

The objective of our study was to evaluate women's choice in the method of cervical ripening and to compare women satisfaction according to their choice.

\section{MATERIALS AND METHODS}

Study design and participants

This is a prospective cohort study carried out at the Paule de Viguier Hospital in Toulouse from July 2019 until October 2020. This hospital is a tertiary care center for neonatal care with 5200 newborns born each year.

The medical healthcare professionals implemented a new protocol in February 2019 in order to offer women the choice of the method of labour induction.

In order to optimize our patient care and to facilitate the women's choice, a booklet with information on the three different methods of labour induction was available in French and English, written in collaboration with patients, midwifes and obstetricians. The booklet described the three different methods of cervical ripening and the most important steps of labour induction.

The protocol of labour induction offered three of the cervical ripening methods available in France: oral misoprostol, PGE2 pessary and balloon catheter. The supra cervical balloon corresponds to a Foley catheter. The balloon is inserted vaginally up until it reaches a supra cervical level and it is filled with $60 \mathrm{ml}$ of saline water. PGE2 pessary, prostaglandin E2, is a vaginal insert, and is placed in the vagina by a midwife. Misoprostol is an oral tablet of 25 micrograms taken every two hours as long as the patient is not in labour, up until a dose of $200 \mathrm{mcg}$ (eight tablets) in total. Whatever the method chosen, after 24 hours of cervical ripening without labour, induction of labour by amniotomy and oxytocin was start in a delivery room.

The study period started four months after the implementation of the new labour induction protocol in order to allow the medical staff to become familiar with this new protocol. During the six months before the beginning of the study, we decided to evaluate women satisfaction about cervical ripening and labour induction without offering them the possibility to choose.

During the study period, we included all pregnant women admitted for labour induction with a singleton pregnancy at term $(37-41+6$ weeks) requiring cervical ripening by either oral misoprostol or PGE2 pessary or Foley catheter.

Exclusion criteria were: any contra-indication to one of the three methods of labour induction, women under 18 years old and patients with no understanding of French or English language. For the use of Foley Catheter, rupture of membranes, coagulation disorder, HIV infection, Hepatitis B or C infection were the main contra-indications. PGE2 pessary contra-indications were intrauterine growth restriction $\left(<3^{\text {rd }}\right.$ centile), history of caesarean delivery or multiparity (strictly more than three). Misoprostol specific contra-indications were severe hepatic or renal insufficiency or previous caesarean section. All participants were included after 
obtaining written informed consent. Intra partum surveillance was similar for all patients and conform to local protocols.

Women's satisfaction was evaluated with the use of a questionnaire available in French and English. The questionnaires were based on the items in the Labour Agentry Scale, an instrument measuring expectancies and experiences of personal control during childbirth ${ }^{16}$. In addition, we used the items studied to develop the CEQ (Childbirth Experience Questionnaire) and QACE (Questionnaire for Assessing the Childbirth Experience) questionnaires. The CEQ measures different aspects of maternal satisfaction with labour and birth ${ }^{17}$. The QACE questionnaire identifies women with a negative experience of childbirth ${ }^{18}$. Finally, we also included the items of the EXIT score, an instrument for assessing women's experience of induction of labour described by Beckman et al ${ }^{19}$.

The first part of the questionnaire was filled in the day of the decision of labour induction and evaluated the women's motivations for their choice (Table S1). We also evaluated their satisfaction about the given information on a five levels scale from 'not at all satisfied' to 'very satisfied'. Finally, we evaluated their satisfaction of being able to choose themselves and the anxiety generated by this choice.

The second part of the questionnaire was given 24 to 72 hours after the delivery and before discharge. This part of the questionnaire evaluated women's satisfaction related to labour induction, pain relief management and their feelings concerning duration of labour induction. Finally, patients were asked to decide which method they would choose for a potential new labour induction in a next pregnancy and if they would recommend the method of their choice.

\section{Outcomes}

Global satisfaction regarding the induction of labour was rated on a scale from one to four. Primary outcome was the global level of satisfaction treated as a binary variable: women were considered satisfied if they scored a three or more and unsatisfied if they scored a two or less ${ }^{16}$.

Secondary outcomes included satisfaction regarding quality of the given information, pain, duration of labour induction, the delivery itself and an evaluation of anxiety. The satisfaction regarding of the quality of the given information, delivery and anxiety were rated on a scale from one to four or five and the variable were analyzed as for the primary outcome.

For the pain and duration of labour induction variables, there were three possible answers, it was less, more or as painful or longer than expected.

Statistical analysis

We compared the characteristics of women, pregnancies and deliveries using Chi-square test or Fisher exact tests for categorical variables and Analysis of variance (ANOVA) or Kruskal-wallis test for quantitative variables, as appropriate. Potential confounders, that might influence both the choice of method of induction and the satisfaction, were determined from previous literature and clinical knowledge. To assess the association between method of induction and satisfaction regarding induction of labour, while controlling for confounders, we used a multivariable logistic regression model. Confounders included in the regression model were: obesity, parity, history of labour induction and indication for labour induction.

Finally, to identify factors associated with global satisfaction, we performed a multivariable logistic regression with stepwise selection. Variables included in the initial regression model were: obesity, parity, history of labour induction, induction method, indication for labour induction, adequate information, satisfaction regarding pain management, assisted vaginal delivery, cesarean delivery, postpartum hemorrhage and delivery within 24 hours after the start of induction. Odds ratios were expressed with their $95 \%$ confidence interval. All tests were two-sided with p-values 0.05 defined as statistically significant. All analyses were performed using R STUDIO version 1.0.136.

The lack of data on women's choice of labour induction did not allow for sample size calculation. Based on the study of Ten Eikelder ML et al., we planned to include more than 500 women. In their study, 502 
patients were included and the authors assessed experience and preferences among term women undergoing induction of labour with oral misoprostol or Foley catheter ${ }^{20}$.

The protocol was approved by the French ethics committee for research in obstetrics and gynaecology (CEROG, reference number 2019-OBS-0602).

\section{RESULTS}

During the study period, 1210 women underwent labour induction. 538 (42.9\%) met the inclusion criteria and were included in our study. The final responsive rate was $96.7 \%$, thus 520 women in total.

The main indications for labour induction were prolonged pregnancy $(37,9 \%)$ gestational diabetes $(26,0 \%)$ and maternal pathologies such as gestational cholestasis, diabetes or placental vascular diseases $(18,8 \%)$. There was a very low rate of induction of labour on-demand at 39 weeks $(1,15 \%)$.

Maternal characteristics are reported in Table 1. Maternal age, pre-pregnancy BMI, ethnicity, pre-existing and/or pregnancy comorbidity, gestational age at induction and initial Bishop score were comparable between groups. Regarding obstetrical outcomes, there was no difference between the three groups in terms of total duration of labour induction, rate of deliveries within 24 hours after the beginning of labour induction, delivery route or rate of instrumental deliveries.

In our population, $67.5 \%$ chose oral misoprostol versus $21 \%$ and $11,5 \%$ respectively for PGE2 pessary and Foley catheter. In the misoprostol group, for $73 \%$ of these women, the main argument for their choice was the oral administration compared to the other two options that are vaginal. 18.5\% mentioned that taking the medication themselves gave them an active role in their labour induction. 21\% of patients chose PGE2 pessary. They justified their choice in $51.4 \%$ of cases by the intravaginal administration. $22.9 \%$ argumented that they had been advised by their entourage. Finally, 11,5\% of patients chose to be induced with a Foley catheter, $80 \%$ of which said to be attracted by the non-pharmacological character of this device.

Regarding our main outcome, we found no significant difference between the three groups with global satisfaction, rates being quite similar $78,4 \%, 68,8 \%$ and $71,2 \%(\mathrm{p}=0,091)$ for oral misoprostol, PGE2 pessary and Foley catheter respectively (Table 2).

The global satisfaction of labour induction was $72,8 \%$, compared to $36 \%$ in the period without offering women the choice of the cervical ripening method $(\mathrm{p}<0.001)$.

$93.4 \%$ of the patients reported that the information they received about the several methods of labour induction was sufficient. $95,2 \%$ of the patients were satisfied with their final choice and only $3,65 \%$ of the women mentioned that having the choice increased their anxiety.

$52,3 \%$ of the patients in the PGE2 pessary group mentioned that labour induction method was more painful than expected, vs $27.1 \%$ and $34.5 \%$ in the Foley catheter group and in the misoprostol group respectively $(\mathrm{p}<0,001)$. We found a significant difference in what method women would choose for a future labour induction: $56,7 \%$ of patients in the PGE2 pessary group would make the same choice compared to $77,7 \%$ and $72,4 \%$ in the misoprostol and the Foley catheter group $(\mathrm{p}<0,001)$. There was no significant difference in global satisfaction concerning delivery between the chosen method of induction. $97 \%$ of the patients felt their choices had been respected during labour induction without significant difference between the three groups.

Finally, we identified that nulliparity $(\mathrm{OR}=2.03,95 \% \mathrm{CI}[1.19-3.53])$, delivery within 24 hours after the start of induction $(\mathrm{OR}=3.46,95 \% \mathrm{CI}$. $[2.02-6.14])$ and adequate information (OR $=4.21,95 \% \mathrm{CI}[1.86$ 9.64]) were significantly associated with greater satisfaction (Table 3).

Factors associated with lower satisfaction were the occurrence of postpartum hemorrhage $(\mathrm{OR}=0.51,95 \% \mathrm{CI}$ $[0.30-0.88])$ and cesarean section $(\mathrm{OR}=0.31,95 \% \mathrm{CI}[0.17-0.54])$.

\section{DISCUSSION}




\section{Main findings}

To our knowledge, this is the first prospective study reporting the direct implication of women's choices in the decision of the method of cervical ripening for labour induction, by comparing three methods. Women were highly satisfied with to be consulted about their preference and to be involved in the labour induction process. However, there was no significant difference in satisfaction rates according to the chosen method. Taking into account the opinion of patients medical decision making is necessary, especially at a time as important as their delivery.

Strengths and limitations

Strengths of this study include the prospective design and the important sample size. The tight management of our study allowed us to have few patients lost to follow up. Finally, we think the innovative and unique character of this study is a real strength.

However, this study also has some limitations. First of all, there might exist a subjective bias due to absence of homogeneity in the way of counseling about the different types of labour induction. All the caregivers in our maternity had agreed to participate. However, we have an imperative in the protocol not to influence the choice of patients. This reflected in the fact that $96 \%$ of patients reported that their choice was respected. Secondly, the monocentric character of the study does not allow for overall generalization of the results.

Although all patients were evaluated at the same interval after the delivery, the short period of time between the delivery and the evaluation of their choice (one-three days postpartum) can be a point of discussion. ${ }^{21}$ Finally, our study was not designed nor powered to compare obstetrical and neonatal outcomes.

Interpretation

Cervical ripening by oral misoprostol was most frequently chosen method $(67,5 \%)$ which is in line with other studies reporting that oral administration is preferred over vaginal administration in the setting of miscarriage management ${ }^{22,23}$. In Colon et al. study, $14 \%$ percent of women in the vaginal group versus $7.5 \%$ in the oral group were dissatisfied with the use of misoprostol ${ }^{22}$. Moreover, in our study, $18.5 \%$ of the included women preferred oral misoprostol because they felt to have an active role in their cervical ripening by taking tablets themselves.

PGE2 pessary is associated with more pain than expected and is the method the less frequently chosen for a next labour induction. In his study, Wang at al. compared Foley catheters to PGE2 pessary and he also found a lower pain score in favor of Foley catheter $(4.87+-1.01 \text { vs. } 5.64+-1.03 ; P<0.001)^{24}$.

We found a satisfaction level slightly higher than reported in recent literature, for example in the study of Shetty ${ }^{25}$, more than one third of patients stated not to be satisfied with the received information against only $7 \%$ in our study. Our results emphasize the importance of clear and precise information in the particular situation of labour induction. In our study, the high rate of satisfaction regarding the information received about labour induction is the result of a particular involvement of caregivers as well as the detailed booklet given to each patient. Patient associations were involved in writing the protocol and the information booklet, which may partly contribute to the high level of satisfaction. Similarly, Coates et al. highlights the causality between received information and patient satisfaction ${ }^{15}$. Finally, it is important to emphasize that anxiety about the choice of their method was increased in only $3,7 \%$ of patients.

Factors associated with patient satisfaction according to our study were concordant with previous studies 14,26 : primiparity, delivery within 24 hours after start of labour induction and the quality of the received information.

Factors associated with a worse patient satisfaction are caesarian delivery (OR : 0,31 [0,17-0,54]) and the occurrence of postpartum hemorrhage [OR 1.3 (95\% CI 1.1-1.6)] which is also in agreement with previous studies ${ }^{14,26}$. 
Improving the understanding of women's perceptions of their childbirth experience during the perinatal period has gained interest from researchers and health practitioners in obstetrics ${ }^{18}$. A positive experience can lead to a sense of accomplishment and feelings of self-worth and self-confidence. Nowadays, the involvement of women in their own care appears essential, especially considering obstetrical care such as labour induction. We believe it is essential to involve patients in their own care and in medical decision making. Although we had a simplified booklet, the information mode can be further improved, especially for patients with reading difficulties. A video or an illustrated folder might be created in order to better adapt the information to this population.

Also, one of the evolutions of integrating the women's choice in the final decision could be to allow outpatient labour induction in a low risk population as recently described $27,28,29$. Helmig et al. reported that $72 \%$ of patients chose to have cervical ripening at home when possible ${ }^{30}$. Kruit et al. reported a high rate of satisfaction of $85,3 \%$ in patients induced at home ${ }^{31}$.

\section{CONCLUSION}

To conclude, it is an innovative study that considers women's opinion about obstetrical management, a challenge in modern obstetrics ${ }^{32,2}$. By offering women the choice about the method of cervical ripening for labour induction, we observe an unequal repartition between the three groups with a majority of women choosing oral misoprostol. However, the level of satisfaction is similar between the three considered methods. These results should encourage obstetrical care givers to involve women in the different options of labour induction management.

\section{Disclosure of interests}

The authors declare to have no conflict of interest. Full disclosures of interests are available to view online as supporting information.

\section{Contribution to authorship}

All authors participated in the editing of this manuscript and approved the final version for publication. ND was involved in the conception and planning of the study, the acquisition and interpretation of data. LL was involved in the analysis and interpretation of the data and provided statistical advice. PLMD was involved in the interpretation of the data and the revision of the article. OP an CV participated in the interpretation of the results and made suggestions for revisions. PG conceived and designed the study, was involved in the analysis and interpretation of data, and the cowriting and critical revision of the article.

\section{Details of ethical approval}

The protocol was approved by the French ethics committee for research in obstetrics and gynaecology on 07/01/2019 (CEROG, reference number 2019-OBS-0602).

\section{Funding}

The study received no external funding.

\section{Acknowledgements}

We thank all of the mothers for participating in the study.

\section{References}

1. Martin JA, Hamilton BE, Osterman MJK, Driscoll AK, Drake P. Births: Final Data for 2017. Natl Vital Stat Rep Cent Dis Control Prev Natl Cent Health Stat Natl Vital Stat Syst. 2018 Nov;67(8):1-50.

2. Declercq E, Belanoff C, Iverson R. Maternal perceptions of the experience of attempted labor induction and medically elective inductions: analysis of survey results from listening to mothers in California. BMC Pregnancy Childbirth. 2020 Dec;20(1):458. 
3. Alfirevic Z, Keeney E, Dowswell T, Welton N, Medley N, Dias S, et al. Methods to induce labour: a systematic review, network meta-analysis and cost-effectiveness analysis. BJOG Int J Obstet Gynaecol. 2016 Aug;123(9):1462-70.

4. Seijmonsbergen-Schermers AE, van den Akker T, Rydahl E, Beeckman K, Bogaerts A, Binfa L, et al. Variations in use of childbirth interventions in 13 high-income countries: A multinational cross-sectional study. Stock SJ, editor. PLOS Med. 2020 May 22;17(5):e1003103.

5. Blondel B, Coulm B, Bonnet C, Goffinet F, Le Ray C, National Coordination Group of the National Perinatal Surveys. Trends in perinatal health in metropolitan France from 1995 to 2016: Results from the French National Perinatal Surveys. J Gynecol Obstet Hum Reprod. 2017 Dec;46(10):701-13.

6. Blanc-Petitjean P, Salome M, Dupont C, Crenn-Hebert C, Gaudineau A, Perrotte F, et al. Etat des lieux des pratiques de declenchement en France. Gynecologie Obstetrique Fertil Senologie. 2019 Jul;47(7-8):55561.

7. Grobman WA, Rice MM, Reddy UM, Tita ATN, Silver RM, Mallett G, et al. Labor Induction versus Expectant Management in Low-Risk Nulliparous Women. N Engl J Med. 2018 Aug 9;379(6):513-23.

8. ten Eikelder ML, Neervoort F, Rengerink KO, Jozwiak M, de Leeuw J-W, de Graaf I, et al. Induction of labour with a Foley catheter or oral misoprostol at term: the PROBAAT-II study, a multicentre randomised controlled trial. BMC Pregnancy Childbirth. 2013 Dec;13(1):67.

9. Chen W, Xue J, Peprah M, Wen S, Walker M, Gao Y, et al. A systematic review and network metaanalysis comparing the use of Foley catheters, misoprostol, and dinoprostone for cervical ripening in the induction of labour. BJOG Int J Obstet Gynaecol. 2016 Feb;123(3):346-54.

10. National Collaborating Centre for Women's and Children's Health (UK). Induction of Labour [Internet]. London: RCOG Press; 2008 [cited 2021 May 19]. (National Institute for Health and Clinical Excellence: Guidance). Available from: http://www.ncbi.nlm.nih.gov/books/NBK53617/

11. HAS - Haute Autorite de Sante. Declenchement artificiel du travail a partir de 37 semaines d'amenorrhee. Rev Sage-Femme. 2009 Feb;8(1):53-6.

12. Hodnett E. Pain and women's satisfaction with the experience of childbirth: A systematic review*1. Am J Obstet Gynecol. 2002 May;186(5):S160-72.

13. Hodnett ED, Hannah ME, Weston JA, Ohlsson A, Myhr TL, Wang EEI, et al. Women's Evaluations of Induction of Labor Versus Expectant Management for Prelabor Rupture of the Membranes at Term. Birth. 1997 Dec;24(4):214-20.

14. Adler K, Rahkonen L, Kruit H. Maternal childbirth experience in induced and spontaneous labour measured in a visual analog scale and the factors influencing it; a two-year cohort study. BMC Pregnancy Childbirth. 2020 Dec;20(1):415.

15. Coates D, Goodfellow A, Sinclair L. Induction of labour: Experiences of care and decision-making of women and clinicians. Women Birth. 2020 Feb;33(1):e1-14.

16. Hodnett ED, Simmons-Tropea DA. The labour agentry scale: Psychometric properties of an instrument measuring control during childbirth. Res Nurs Health. 1987 Oct;10(5):301-10.

17. Dencker A, Taft C, Bergqvist L, Lilja H, Berg M. Childbirth experience questionnaire (CEQ): development and evaluation of a multidimensional instrument. BMC Pregnancy Childbirth. 2010 Dec;10(1):81.

18. Carquillat P, Vendittelli F, Perneger T, Guittier M-J. Development of a questionnaire for assessing the childbirth experience (QACE). BMC Pregnancy Childbirth. 2017 Dec;17(1):279.

19. Beckmann M, Thompson R, Miller Y, Prosser SJ, Flenady V, Kumar S. Measuring women's experience of induction of labor using prostaglandin vaginal gel. Eur J Obstet Gynecol Reprod Biol. 2017 Mar;210:189-95. 
20. ten Eikelder M, van de Meent M, Mast K, Rengerink K, Jozwiak M, de Graaf I, et al. Women's Experiences with and Preference for Induction of Labor with Oral Misoprostol or Foley Catheter at Term. Am J Perinatol. 2016 Jun 24;34(02):138-46.

21. Soet JE, Brack GA, DiIorio C. Prevalence and Predictors of Women's Experience of Psychological Trauma During Childbirth. Birth. 2003 Mar;30(1):36-46.

22. Colon I, Clawson K, Hunter K, Druzin ML, Taslimi MM. Prospective randomized clinical trial of inpatient cervical ripening with stepwise oral misoprostol vs vaginal misoprostol. Am J Obstet Gynecol. 2005 Mar;192(3):747-52.

23. Alfirevic Z, Aflaifel N, Weeks A. Oral misoprostol for induction of labour. Cochrane Pregnancy and Childbirth Group, editor. Cochrane Database Syst Rev [Internet]. 2014 Jun 13 [cited 2020 Nov 7]; Available from: http://doi.wiley.com/10.1002/14651858.CD001338.pub3

24. Wang L, Wang G, Cao W, Guo L, Hu H, Li Y, et al. Comparison of the Cook vaginal cervical ripening balloon with prostaglandin E2 insert for induction of labor in late pregnancy. Arch Gynecol Obstet. 2020 Sep;302(3):579-84.

25. Shetty A, Burt R, Rice P, Templeton A. Women's perceptions, expectations and satisfaction with induced labour-A questionnaire-based study. Eur J Obstet Gynecol Reprod Biol. 2005 Nov;123(1):56-61.

26. Henderson J, Redshaw M. Women's experience of induction of labor: a mixed methods study. Acta Obstet Gynecol Scand. 2013 Jul;n/a-n/a.

27. Turnbull D, Adelson P, Oster C, Bryce R, Fereday J, Wilkinson C. Psychosocial Outcomes of a Randomized Controlled Trial of Outpatient Cervical Priming for Induction of Labor. Birth. 2013 Jun;40(2):75-80.

28. Amorosa JMH, Stone JL. Outpatient cervical ripening. Semin Perinatol. 2015 Oct;39(6):488-94.

29. Stephenson E, Borakati A, Simpson I, Eedarapalli P. Foley catheter for induction of labour: a UK observational study. J Obstet Gynaecol. 2020 Nov 16;40(8):1064-8.

30. Helmig RB, Hvidman LE. An audit of oral administration of Angusta(r) (misoprostol) $25 \mu \mathrm{g}$ for induction of labor in 976 consecutive women with a singleton pregnancy in a university hospital in Denmark. Acta Obstet Gynecol Scand. 2020 Oct;99(10):1396-402.

31. Kruit H, Heikinheimo O, Ulander V-M, Aitokallio-Tallberg A, Nupponen I, Paavonen J, et al. Foley catheter induction of labor as an outpatient procedure. J Perinatol. 2016 Aug;36(8):618-22.

32. Doyle C, Lennox L, Bell D. A systematic review of evidence on the links between patient experience and clinical safety and effectiveness. BMJ Open. 2013;3(1):e001570.

Table 1: Maternal demographics and baseline characteristics

\begin{tabular}{lllll}
\hline & $\begin{array}{l}\text { FOLEY } \\
\text { CATHETER }\end{array}$ & $\begin{array}{l}\text { ORAL } \\
\text { MISOPROSTOL }\end{array}$ & PGE2 PESSARY & p value \\
\hline & $\mathrm{N}=60 \mathrm{n}(11,5 \%)$ & $\begin{array}{l}\mathrm{N}=351 \mathrm{n} \\
(67,5 \%)\end{array}$ & $\mathrm{N}=109 \mathrm{n}(21 \%)$ & \\
Age $(\mathrm{y})$ & $32[28.75-35]$ & $31[27-35]$ & $31[28-35]$ & 0.69 \\
BMI (kg/m2) & $22[20.75-25]$ & $25[20.75-25]$ & $24[21-28]$ & 0.10 \\
Obesity & $6(10.0)$ & $77(21.9)$ & $21(19.3)$ & 0.10 \\
Ethnicity & & & & 0.47 \\
Caucasian & $46(76.7)$ & $230(65.5)$ & $81(74.3)$ & \\
North African & $10(16.7)$ & $84(23.9)$ & $9(8.2)$ & \\
Subsaharian & $4(6.7)$ & $24(6.8)$ & &
\end{tabular}




\begin{tabular}{|c|c|c|c|c|}
\hline & $\begin{array}{l}\text { FOLEY } \\
\text { CATHETER }\end{array}$ & $\begin{array}{l}\text { ORAL } \\
\text { MISOPROSTOL }\end{array}$ & PGE2 PESSARY & $\mathrm{p}$ value \\
\hline$\overline{\text { Asia }}$ & 0 & $4(1.1)$ & $1(0.9)$ & \\
\hline Other & 0 & $9(2.6)$ & $2(1.8)$ & \\
\hline Comorbidities & & & & \\
\hline $\begin{array}{l}\text { Chronic } \\
\text { hypertension }\end{array}$ & 0 & $9(2.6)$ & $4(3.7)$ & 0.34 \\
\hline $\begin{array}{l}\text { Pre-existing } \\
\text { diabetes }\end{array}$ & 0 & $14(4)$ & $4(3,7)$ & 0,58 \\
\hline Parity & & & & 0.77 \\
\hline $\begin{array}{l}\text { Nulliparity } \\
\text { Pregnancy } \\
\text { complications }\end{array}$ & $40(66.7)$ & $217(61.8)$ & $68(62.4)$ & \\
\hline $\begin{array}{l}\text { Gestational } \\
\text { hypertension }\end{array}$ & $3(5.0)$ & $18(5.1)$ & $7(6.4)$ & 0.87 \\
\hline Preeclampsia & 0 & $22(6.3)$ & $6(5.5)$ & 0.12 \\
\hline $\begin{array}{l}\text { Gestational } \\
\text { diabetes }\end{array}$ & $15(25.0)$ & $114(32.5)$ & $25(22.9)$ & 0.11 \\
\hline $\begin{array}{l}\text { GA at labour } \\
\text { induction }\end{array}$ & $39.7[38.9-41.3]$ & $39.4[38.9-41]$ & $39.4[38.7-41.3]$ & 0.61 \\
\hline $\begin{array}{l}\text { Initial Bishop } \\
\text { score }\end{array}$ & $1[0-3]$ & $1[0-3]$ & $1[0-3]$ & 0.88 \\
\hline $\begin{array}{l}\text { Duration of } \\
\text { labour } \\
\text { induction }\end{array}$ & $36[27-43.25]$ & $28[20.5-37]$ & $31[19-39]$ & 0.09 \\
\hline $\begin{array}{l}\text { Delivery within } \\
24 \text { hours } \\
\text { Mode of } \\
\text { delivery }\end{array}$ & $13(21.7)$ & $131(37.3)$ & $37(34.3)$ & 0.06 \\
\hline Vaginal delivery & $48(80)$ & $271(77.2)$ & $81(75)$ & 0.76 \\
\hline $\begin{array}{l}\text { Instrumental } \\
\text { delivery }\end{array}$ & $5(8.3)$ & $51(14.5)$ & $18(16.7)$ & 0.32 \\
\hline Caesarean section & $12(20)$ & $80(22.8)$ & $27(25.0)$ & 0.76 \\
\hline
\end{tabular}

Data are shown as median [interquartile range] or number (\%).

BMI, body mass index; GA, Gestational Age

\begin{tabular}{llllll}
\hline & $\begin{array}{l}\text { FOLEY } \\
\text { CATHETER }\end{array}$ & $\begin{array}{l}\text { ORAL MISO- } \\
\text { PROSTOL }\end{array}$ & $\begin{array}{l}\text { PGE2 } \\
\text { PESSARY }\end{array}$ & $\begin{array}{l}\text { Univariate } \\
\text { analysis } \mathbf{p} \\
\text { value }\end{array}$ & $\begin{array}{l}\text { Multivariate } \\
\text { analysis * } \mathbf{p} \\
\text { value }\end{array}$ \\
\hline $\begin{array}{l}\mathrm{N}=60 \mathrm{n} \\
(11,5 \%)\end{array}$ & $\begin{array}{l}\mathrm{N}=351 \mathrm{n} \\
(67,5 \%)\end{array}$ & $\begin{array}{l}\mathrm{N}=109 \mathrm{n} \\
(21 \%)\end{array}$ & \\
$\begin{array}{l}\text { Primary } \\
\text { outcome }\end{array}$ & $42(71.2)$ & $272(78.4)$ & $75(68.8)$ & 0.091 & 0.107 \\
$\begin{array}{l}\text { Global } \\
\text { satisfaction } \\
\begin{array}{l}\text { Secondary } \\
\text { outcome }\end{array}\end{array}$ & & & & \\
$\begin{array}{l}\text { Pain } \\
\text { valn }\end{array}$ & $16(27.1)$ & $120(34.5)$ & $57(52.3)$ & $<0,001$ & $<0,001$
\end{tabular}




\begin{tabular}{|c|c|c|c|c|c|}
\hline & $\begin{array}{l}\text { FOLEY } \\
\text { CATHETER }\end{array}$ & $\begin{array}{l}\text { ORAL MISO- } \\
\text { PROSTOL }\end{array}$ & $\begin{array}{l}\text { PGE2 } \\
\text { PESSARY }\end{array}$ & $\begin{array}{l}\text { Univariate } \\
\text { analysis } p \\
\text { value }\end{array}$ & $\begin{array}{l}\text { Multivariate } \\
\text { analysis * p } \\
\text { value }\end{array}$ \\
\hline $\begin{array}{l}\text { Satisfaction of } \\
\text { pain } \\
\text { management }\end{array}$ & $49(83.1)$ & $302(86.8)$ & $89(81.7)$ & 0.368 & 0.574 \\
\hline $\begin{array}{l}\text { Perception of } \\
\text { duration of } \\
\text { induction }\end{array}$ & $29(49.2)$ & $207(59.3)$ & $62(56.9)$ & 0.334 & 0.408 \\
\hline $\begin{array}{l}\text { Vaginal } \\
\text { exams }\end{array}$ & & & & 0.787 & 0.634 \\
\hline Too much & $1(1.7)$ & $14(4.0)$ & $4(36.7)$ & & \\
\hline Adapted & $49(83.1)$ & $277(79.6)$ & $92(84.4)$ & & \\
\hline Insufficient & $9(15.3)$ & $57(16.4)$ & $13(11.9)$ & & \\
\hline $\begin{array}{l}\text { Same } \\
\text { method for a } \\
\text { future } \\
\text { induction }\end{array}$ & $42(72.4)$ & $265(77.7)$ & $60(56.6)$ & $<0,001$ & $<0,001$ \\
\hline $\begin{array}{l}\text { Feeling of } \\
\text { respect } \\
\text { about their } \\
\text { wishes }\end{array}$ & $57(96.6)$ & 336 (97.1) & $107(98.2)$ & 0.794 & 0.713 \\
\hline $\begin{array}{l}\text { Recommended } \\
\text { method for } \\
\text { relatives }\end{array}$ & $45(76.3)$ & $294(85.5)$ & $79(73.1)$ & 0.008 & 0.007 \\
\hline $\begin{array}{l}\text { Satisfaction } \\
\text { delivery }\end{array}$ & $54(91.5)$ & $324(93.6)$ & $101(92.7)$ & 0.686 & 0.833 \\
\hline
\end{tabular}

Table 2: Primary and secondary outcomes

Data are $n$ (\%) unless otherwise specified.

${ }^{*}$ multivariate analysis adjusted on history of labour induction, indication of labour induction, parity and obesity.

Table 3: Variables associated with satisfaction

\begin{tabular}{lll}
\hline & OR & $\mathbf{9 5 \%}$ CI \\
\hline Method of labour induction & & \\
Foley catheter & ref & \\
Oral misoprostol & 1.32 & {$[0.66-2.56]$} \\
PGE2 pessary & 0.78 & {$[0.36-1.64]$} \\
Indication of labour induction & & \\
Term & ref & \\
Maternal pathology & 1.04 & {$[0.58-1.92]$} \\
Gestational diabetes or macrosomia & 2.17 & {$[1.20-4.02]$} \\
On-demand & 1.16 & {$[1.00-1.35]$} \\
Placental pathology & 0.98 & {$[0.52-1.89]$} \\
Nulliparity & 2.03 & {$[1.19-3.53]$} \\
Adequate information & 4.21 & {$[1.86-9.64]$} \\
Instrumental delivery & 1.08 & {$[0.53-2.32]$}
\end{tabular}




\begin{tabular}{lll}
\hline & OR & 95\% CI \\
\hline Caesarean section & 0.31 & {$[0.17-0.54]$} \\
Delivery within 24 hours & 3.46 & {$[2.02-6.14]$} \\
Postpartum hemorrhage & 0.51 & {$[0.30-0.88]$} \\
\hline
\end{tabular}

OR, Odds ratio ; CI, Confidence interval 